\title{
'They Don't Ask Me So I Don't Tell Them': Patient-Clinician Communication About Traditional, Complementary, and Alterna- tive Medicine
}

\author{
Brian M. Sbelley, $M D^{1,2}$ \\ Andrew L. Sussman, PbD, MCRP ${ }^{2}$ \\ Robert L. Williams, $M D, M P H^{2}$ \\ Alissa R. Segal, PharmD $D^{3,4}$ \\ Benjamin F. Crabtree, $P b D^{5}$ \\ on bebalf of the RIOS Net \\ Clinicians \\ 'First Choice Community Healthcare, \\ Albuquerque, New Mexico \\ ${ }^{2}$ Department of Family and Community \\ Medicine, University of New Mexico, \\ Albuquerque, New Mexico \\ ${ }^{3}$ Department of Pharmacy Practice, Mas- \\ sachusetts College of Pharmacy \& Health \\ Sciences, Boston, Massachusetts \\ ${ }^{4}$ Joslin Diabetes Center, Boston, \\ Massachusetts \\ ${ }^{5}$ Department of Family Medicine, Univer- \\ sity of Medicine and Dentistry of New Jer- \\ sey, Robert Wood Johnson Medical School, \\ New Brunswick, New Jersey
}

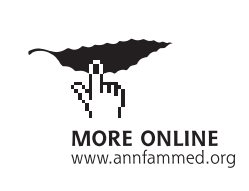

Conflicts of interest: none reported

\section{CORRESPONDING AUTHOR}

Brian M. Shelley, MD

First Choice Community Healthcare

South Valley Family Health Commons

2001 N Centro Familiar, SW

Albuquerque, NM 87105

bshelley@salud.unm.edu

\begin{abstract}
PURPOSE Although high rates of traditional medicine and complementary and alternative medicine (TM/CAM) use have been well documented, there has been less attention to the factors influencing communication between patients and their primary care clinicians about TM/CAM. Such communication can be important in anticipating possible drug-herb interactions and in assuring agreement about therapeutic plans.
\end{abstract}

METHODS We used sequential, multistage, qualitative methods, including focus groups, in-depth interviews, and a video vignette, to explore communication about TM/CAM between patients and their primary care clinicians. The study was conducted in RIOS Net (Research Involved in Outpatient Settings Network), a Southwestern US practice-based research network, situated largely in Hispanic and American Indian communities where TM/CAM is an important part of self-care.

RESULTS One hundred fourteen patients, 41 clinic staff members, and 19 primary care clinicians in 8 clinic sites participated. The degree and nature of TM/ CAM communication is based on certain conditions in the clinical encounter. We categorized these findings into 3 themes: acceptance/nonjudgment, initiation of communication, and safety/efficacy. Perceived clinician receptivity to and initiation of discussion about TM/CAM strongly influenced patients' decisions to communicate; perceived clinician expertise in TM/CAM was less important. Clinicians' comfort with patients' self-care approaches and their level of concern about lack of scientific evidence of effectiveness and safety of TM/CAM influenced their communication about TM/CAM with patients.

CONCLUSIONS Specific communication barriers limit patient-clinician communication about TM/CAM. Clinicians who wish to communicate more effectively with their patients about these topics and better integrate the types of care their patients use can change the communication dynamic with simple strategies designed to overcome these barriers.

Ann Fam Med 2009;7:139-147. DOI: 10.1370/afm.947.

\section{INTRODUCTION}

$\mathrm{T}$

The use of traditional, complementary, and alternative medicine is widespread, ${ }^{1-4}$ although most users of traditional medicine and complementary and alternative medicine $(\mathrm{TM} / \mathrm{CAM})^{2}$ also use allopathic care. ${ }^{3}$ There are numerous studies, however, documenting a lack of communication in the conventional care setting between patients and their primary care clinicians about patients' use of TM/CAM. ${ }^{5-7}$

Patient-centered communication is an evolving construct unified by a set of core values defined by Epstein et al as a set of strategies (or a "way of being") designed to enhance a sense of partnership in the patient-clinician 
relationship. ${ }^{8}$ Applied to TM/CAM use, patient-centered communication can be important because it may (1) result in closer agreement between the clinician and patient about treatment plans, (2) reduce misunderstandings between patients and clinicians, (3) uncover potential herb-drug interactions, (4) strengthen the quality of the patient-clinician relationship, and (5)

Figure 1. Study methods. Stages of data collection with interspersed immersion/ crystallization analytic steps.

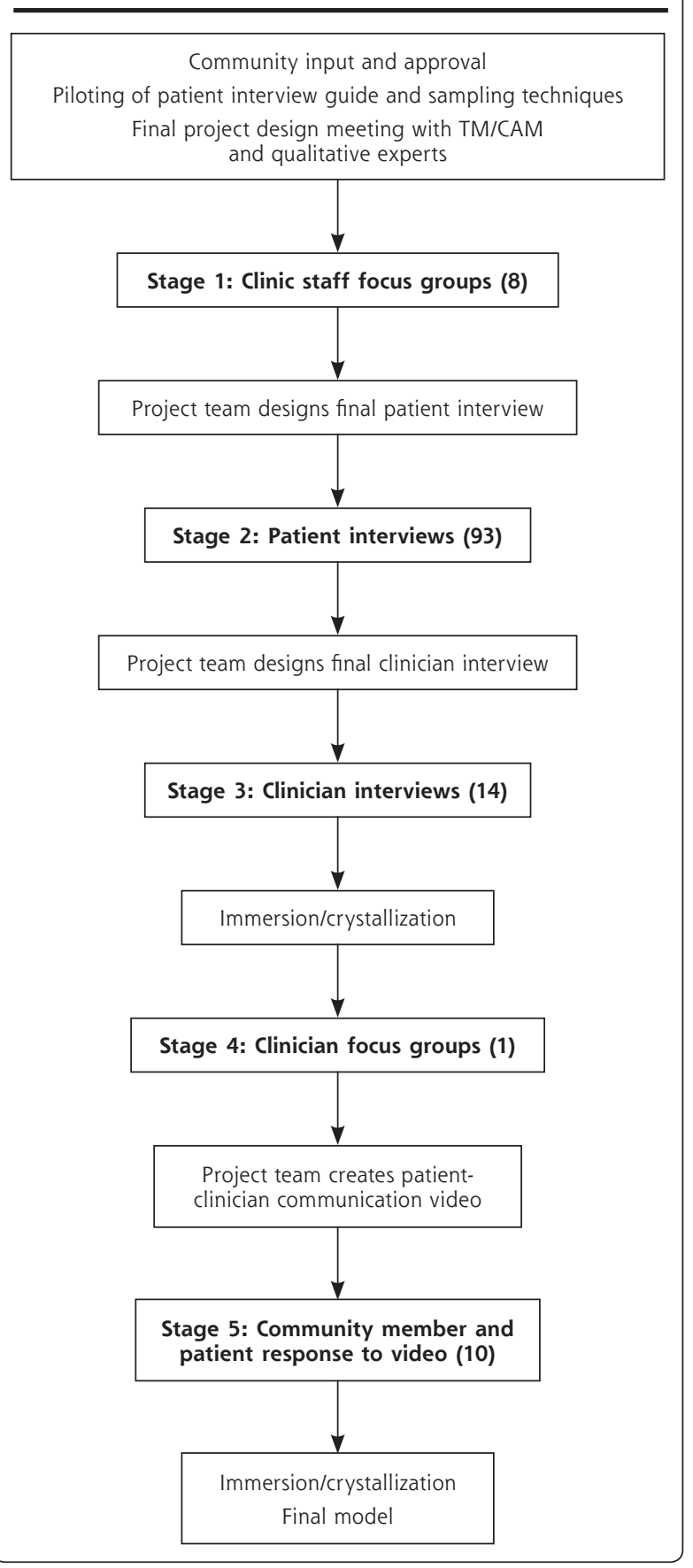

provide an opportunity to discuss specific TM/CAM modalities with high-quality evaluative evidence. ${ }^{9-11}$

A first step toward improving communication between patients and their primary care clinicians about TM/CAM use is to better understand the factors influencing that communication. We conducted a qualitative study to explore the dynamics driving and inhibiting communication between clinicians and their patients about TM/CAM. Our specific aims were to compare perspectives of patients and primary care clinicians on communication about TM/CAM, and to identify strategies for enhancing patient-clinician communication about TM/CAM.

\section{METHODS}

\section{Design}

We conducted this study in Southwestern Hispanic and Native American communities in New Mexico where TM/CAM use is common. ${ }^{12-19}$ We carried out a multistage qualitative study using focus groups, in-depth interviews, and a video vignette to investigate processes of communication about TM/CAM. The 5 stages of the design were (1) focus groups composed of clinic staff and community key informants; (2) interviews of patients being seen in clinic; (3) interviews of clinicians in the same clinics; (4) an analytic focus group of clinicians from other clinics; and (5) reflective interviews of community members and patients being seen in the clinics using a video vignette (Figure 1 displays an overview of the study design). Experience with and findings from each stage informed the subsequent stage.

\section{Setting}

We conducted the study in the Research Involved in Outpatient Settings Network (RIOS Net, http://hsc. unm.edu/rios), a primary care practice-based research network in New Mexico with 250 member clinicians practicing in community health centers, Indian Health Service clinics, and academic and private practices. These primary care sites largely serve low-income, predominantly Hispanic and Native American communities. ${ }^{20-22}$ The study protocol was approved by community groups and by 4 institutional review boards.

\section{Stage 1. Clinic Staff Focus Groups Population Sample}

Using a purposive sampling strategy guided by a priori expectations about important factors in TM/CAM practices (rural vs urban setting, Hispanic and Native American culture), we selected 8 communities and associated clinics in the RIOS Network. Of the 8 clinics, 2 each served, respectively, primarily urban Hispanics, rural Hispanics, urban Native Americans, and 
rural Native Americans. Hispanics in these communities and clinics were both immigrant and native-born, and Native Americans were Navajo and Pueblo. In each location we recruited 3 to 5 clinic staff members and community key informants for a focus group to explore local context and terminology of TM/CAM

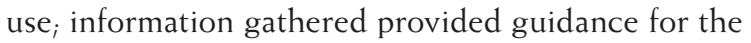
subsequent patient-based stage. ${ }^{23}$

\section{Data Collection}

Using a semistructured focus group guide, we explored the methods of discussing TM/CAM with patients, the TM/CAM language specific to their community and culture, and the observations on patients' discussions of TM/CAM with their clinicians (Supplemental Appen-

org/cgi/content/full/7/2/139/DC1). Two research team members moderated each group. Discussions lasted 45 to 60 minutes and were recorded and transcribed. Group members received compensation for their participation.

\section{Data Analysis}

Using an editing analytic approach, ${ }^{24} 3$ members of the research team independently reviewed each focus group transcript. The team then met to discuss themes in the data and to modify the patient and clinician interview guides, as needed, to place the interviews within the local context. Group transcripts were also imported into $\mathrm{NVivo}^{25}$ for coding and text retrieval.

\section{Stage 2. In-Depth Patient Interviews Sample}

Using a purposive sampling strategy, we interviewed patients at each clinic site as they came in for care $(n=93)$. Patients were selected to represent a range of ages, including children (whose parents were the interviewees), and were recruited in outpatient waiting areas. Patients were chosen regardless of apparent openness to TM/CAM, medical condition, or length of relationship with clinicians. We recruited 8 to 15 patients at each site, continuing overall recruitment until data saturation (no new data themes) was reached.

\section{Data Collection}

Using a brief, semistructured patient interview guide, we explored community use of TM/CAM, personal experience with TM/CAM and allopathic care, and experiences with communication about TM/CAM with clinicians (Supplemental Appendix 2, available

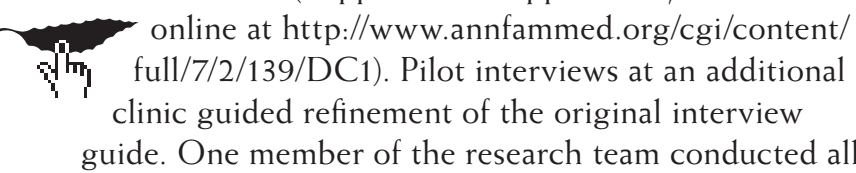

interviews, using Spanish or Navajo speaking translators as needed. Interviews lasted 15 to 20 minutes and were recorded and transcribed. Patients received compensation for participation.

\section{Data Analysis}

Following an immersion/crystallization process, ${ }_{,}^{26}$ members of the research team independently reviewed sets of 6 to 12 transcripts at a time. The team then met to agree on interpretations. Data collection and analysis proceeded in an iterative fashion with minor modifications of the interview guide as needed to test ongoing interpretations and to examine anomalous responses. Transcripts were imported into NVivo for coding and text retrieval. Through this iterative process, we developed a preliminary theoretical framework that we further refined in subsequent data collection steps.

\section{Stage 3. In-Depth Clinician Interviews Sample}

We next purposively sampled 14 clinicians ( 1 to 2 at each study clinic) using variation in years of practice experience and expected attitudes toward TM/CAM as sampling characteristics to capture a variety of perspectives.

\section{Data Collection}

A semistructured interview guide facilitated exploration of factors influencing attitudes toward TM/CAM and experience in communicating with patients about TM/CAM (Supplemental Appendix 3, available online at http://www.annfammed.org/cgi/content/full/ 7/2/139/DC1). Three pilot interviews were conducted with other clinicians. All interviews were conducted by 1 member of the research team, lasted between 45 and 60 minutes, and were recorded and transcribed.

\section{Data Analysis}

Again following an iterative immersion/crystallization process, research team members independently reviewed sets of 2 to 3 transcripts at a time, meeting after each set to discuss emerging themes and to modify the interview guide as needed to test ongoing interpretations and further examine anomalous responses. Transcripts were again imported into NVivo for coding and text retrieval. Through this iterative process, comparing clinician data with patient data, we refined our preliminary theoretical framework.

\section{Stage 4. Analytic Focus Group \\ Sample}

Five additional clinicians participated in an analytic focus group. Group members were recruited using the stage 3 sampling criteria. 


\section{Data Collection}

We used this step as a mechanism to have clinicians refine, confirm, or disconfirm our preliminary interpretations while also providing new data for analysis. The group began with an overview of interview findings and our preliminary model. The group was moderated by 2 team members, recorded, and transcribed.

\section{Data Analysis}

The research team reviewed the group transcript both independently and then collaboratively, searching for comparability to and differences from the analytic framework. We used the refined analytic model resulting from this process for the final step of the research.

\section{Stage 5. Community and Patient Review of Model of Enhanced Communication: Reflective Interviews}

\section{Sample}

We sampled 6 members of the RIOS Net Community Advisory Board, as well as patients in 4 of the participating clinics (1 each serving primarily Hispanic or Native American patients in rural or urban settings). Patients were sampled using the same approach as in stage 2 .

\section{Data Collection}

We produced brief video vignettes of patient-clinician discussions of TM/CAM use (English, Hispanic, and Navajo versions), based on key elements of the refined theoretical framework (Supplemental Appendix 4, available online at

http://www.annfammed. im org/cgi/content/full/7/2/139/

DC1). Patients responded to questions about the acceptability of the vignette clinician's approach to initiating communication about TM/CAM, and their likely responsiveness to this approach. Interviews were recorded and transcribed.

\section{Data Analysis}

Research team members independently reviewed transcripts and then met to resolve differences in interpretation. The analytic goal in this stage was to confirm or disconfirm the 3 key elements of the final theoretical framework through patient responses to viewing a model of this communication style.

\section{RESULTS}

\section{Sample Demographics}

In total, 41 staff participated in the 8 clinic staff focus groups, 93 patients were interviewed, 14 clinicians were interviewed, 5 clinicians participated in the clinician focus group, and 6 community advisory board members and 21 patients participated in the reflective patient interviews. Additional details of the sample are provided in Table 1.

\section{Themes}

We categorized our findings about perspectives of patients and primary care clinicians on communication
Table 1. Demographic Characteristics of All Participants

\begin{tabular}{|c|c|c|c|c|c|}
\hline Characteristics & $\begin{array}{c}\text { Clinic } \\
\text { Staff } \\
(n=41)\end{array}$ & $\begin{array}{c}\text { Patient } \\
\text { Interviews } \\
(n=93)\end{array}$ & $\begin{array}{l}\text { Clinician } \\
\text { Interviews } \\
(n=14)\end{array}$ & $\begin{array}{l}\text { Clinician } \\
\text { Focus } \\
\text { Group } \\
(n=5)\end{array}$ & $\begin{array}{c}\text { Patient-Video } \\
\text { Review } \\
\text { Interviews } \\
(n=21)\end{array}$ \\
\hline Sex, female & 38 & 72 & 4 & 2 & 18 \\
\hline \multicolumn{6}{|l|}{ Ethnicity } \\
\hline Hispanic & - & 40 & - & - & 10 \\
\hline $\begin{array}{l}\text { Non-Hispanic } \\
\text { white }\end{array}$ & - & 5 & - & - & 1 \\
\hline Native American & - & 48 & - & - & 10 \\
\hline \multicolumn{6}{|l|}{ Age, years } \\
\hline$<18$ & - & 4 & - & - & 0 \\
\hline $18-30$ & - & 28 & - & - & 7 \\
\hline $31-44$ & - & 23 & - & - & 5 \\
\hline $45-59$ & - & 18 & - & - & 3 \\
\hline $60+$ & - & 18 & - & - & 3 \\
\hline Missing & - & 2 & - & - & 3 \\
\hline \multicolumn{6}{|l|}{ Education } \\
\hline$<$ High school & - & 29 & - & - & - \\
\hline High school & - & 26 & - & - & - \\
\hline$>$ High school & - & 35 & - & - & - \\
\hline Missing & - & 3 & - & - & - \\
\hline \multicolumn{6}{|l|}{ Practice specialty } \\
\hline Family physicians & - & - & 9 & 4 & - \\
\hline Pediatricians & - & - & 1 & 0 & - \\
\hline Internists & - & - & 2 & 0 & - \\
\hline Midlevel (PA, NP) & - & - & 2 & 1 & - \\
\hline \multicolumn{6}{|l|}{ Institutional setting } \\
\hline $\begin{array}{l}\text { Indian Health } \\
\text { Service }\end{array}$ & 22 & 39 & 6 & 0 & 10 \\
\hline $\begin{array}{l}\text { Community } \\
\text { Health Center }\end{array}$ & 19 & 54 & 8 & 4 & 11 \\
\hline $\begin{array}{l}\text { University of } \\
\text { New Mexico }\end{array}$ & 0 & 0 & 0 & 1 & 0 \\
\hline
\end{tabular}




\begin{tabular}{ll}
\hline Table 2. Model of Enhanced Communication Around \\
TM/CAM in New Mexico & \\
\hline Patients & Clinicians \\
\hline Need to perceive openness & Need to demonstrate openness \\
Need to perceive respect & Need to demonstrate respect \\
Need to perceive interest & Need to demonstrate interest \\
Use driven by cultural identity & Need to initiate discussion \\
Use driven by family history & Can ask about TM/CAM in acute setting \\
Use driven by proximity to home & Can still be clinical and evidence-based \\
Do not have outward characteristics & Need not be content experts \\
\hline TM/CAM = traditional medicine and complementary and alternative medicine.
\end{tabular}

about TM/CAM into 3 general themes: (1) acceptance/ nonjudgment, (2) initiation of communication, and (3) safety/efficacy concerns. Table 2 summarizes the full range of factors that we identified as being important in determining the nature of communication about TM/CAM. We did not observe meaningful differences in responses by the sampling characteristics described above (ethnic group, age, geography); therefore, the thematic results apply equally across these groups.

\section{Acceptance and Nonjudgment}

Patients' perceptions of how their clinicians would react to their use of TM/CAM were generally the most important factor in their openness to discussions with the clinician about this topic. An accepting and nonjudgmental attitude by the clinician contributed to willingness by the patient to reveal use of TM/CAM. Many patients told stories about previous experiences during which they felt rebuked by a clinician for using $\mathrm{TM} / \mathrm{CAM}_{i}$ others avoided the discussion out of fear that the clinician would respond negatively.

[Patient] When my little boy was born, I used to give him herbs for his stomach aches. And I used to come in for his well-child check-up and I wouldn't tell [the doctor] because...I'd be like, "she'll get madder." So I don't tell them that I use herbs on the kids.

[Interviewer] And what makes you think the doctor would get mad?

[Patient] Well, when I had my first little girl they did get mad at me. They told me that I'm not supposed to give them anything for the colic.

Importantly, patients did not expect clinicians to be experts on TM/CAM, beyond having broad awareness of local types of TM/CAM. This attitude appeared to reflect an understanding that TM/CAM is outside the realm of training and expertise of most conventional care clinicians. A community member responding to the video vignette said:
I think they should be genuinely interested, and there is a particular kind of interest where it kind of like shows through. ... But whatever they do, they should be honest, and if they know something, they should be willing to share it, and [if] not, I think they should be very level with the people, as to what they know and what they don't know.

Patients also indicated that the limited clinician knowledge of local TM/CAM practices was not a barrier to initiating communication in this area, as they recognized the limited access that cultural outsiders have to knowledge about TM/CAM.

I don't think he needs to know what songs were sung. And if he doesn't know that much, that's okay, too. As long as he knows that I have tried something else besides, you know, coming to the doctor, to a regular doctor.

Clinicians, for their part, varied in their approach to communicating acceptance or nonacceptance of TM/CAM use. For some clinicians, discussions about TM/CAM were viewed as important in communicating respect for patient autonomy and culture and as a mechanism to enhance the patient-clinician relationship. Although these clinicians often still maintained a degree of caution toward the efficacy, cost, and safety of TM/CAM, it appeared that communicating encouragement of the patient's efforts toward self-care was of equal importance and was linked to the clinician's value in a more comprehensive definition of patient health and wellness.

If they're getting a benefit out of having their aura stroked or something, I don't believe in auras, but I'm not going to even betray with a facial muscle that I don't believe in auras. I'm just going to say, "Great, I think that's great." Because I think anything that somebody does for themselves to try to take care of themselves is a positive.

These clinicians pointed out that the language used to introduce and discuss TM/CAM was critical they emphasized an open and nonjudgmental approach. While rejecting the idea of themselves as content experts in TM/CAM, they emphasized the importance of not dismissing the patient's use of TM/CAM as a way to support a positive therapeutic relationship with potentially greater benefits than what might come from criticizing the TM/CAM practice.

I'm thinking about when a woman is pregnant and you wonder if she uses a sweat lodge. The sweat lodge is really hot, and it's not supposed to be safe for pregnant women. So, I'll say, "Do you sweat?" and she'll say, "Yeah, I like to," and I'll say, "Look, I'd be careful about that while you're pregnant." You have to be careful, you know, [she might think] "That 
guy was a real jerk. He's telling me I can't even do my traditional things. I'm not even going to come back here." You'll lose a patient over this sort of thing because with some people it goes very deep.

Other clinicians considered their role as scientific experts advising their patients and their commitment to "do no harm" as compelling them to warn the patient about concerns they had about TM/CAM practices. These clinicians also mentioned a value in being open and honest with their patients about their clinical views.

There's a lot of shyster kind of stuff out there. A couple years ago there was a diabetic thing that actually had glyburide ground up in it. So I had these people taking this herbal thing. What they were taking, however, was pulverized glyburide and people were having hypoglycemia with it. I have no problem with [patients using TM/CAM]. I just want to make sure that there's no contraindication.

\section{Initiation of Communication}

The differing perspectives between patients and clinicians with regard to the initiation and timing of discussion about TM/CAM influenced communication about this topic. Many patients reported either no or low levels of communication about their TM/CAM use with their primary care clinicians. Patients were generally receptive to, if hesitant about, increasing discussion about TM/CAM, but they consistently expressed a preference for the clinician to initiate the TM/CAM discussion: "In my situation, I don't see myself ever just giving him information or just pouring it out. I think he needs to start the dialogue." Another patient gave the following responses:

[Interviewer] How do you think your doctor would respond if you told them about the other things you were doing?

[Patient] I think sometimes they don't believe they work. But a lot of people are going for that, and I think they do work.

[Interviewer] Is that why you don't discuss it, or is there another reason?

[Patient] No, they don't ask me, so I don't tell them.

In contrast, clinicians often did not perceive high levels of TM/CAM use among their patients, and therefore would not initiate the conversation.

[Interviewer] So, where does TM/CAM fit in your hierarchy of things?

[Clinician] I think if I heard more of it coming from my patients, I would feel more stimulated to go out there and get myself informed. But if they're not bringing it up, then I'm not.

At the same time, we found that many clinicians believed their own understanding of the TM/CAM practices their patients were using was insufficient to be able to discuss the practices intelligently or to provide scientifically based medical advice to their patients should the topic come up. This perceived lack of understanding appeared to act as a barrier to the clinician in initiating discussions about TM/CAM.

If you're interested in Pap smears or mammograms, I would be more than happy to help you with that, but on the other stuff, trying St John's Wort or whatever for your depression, don't come to me. I mean, that's the depth of my herbal depression knowledge. I don't know how many times a day, I don't know what brand, I don't know what dosage.

If the clinician did initiate a discussion about TM/ CAM, the phrasing of questions appeared to be important. Patients seemed not to understand that a question about what else he or she is taking is a question about TM/CAM use, assuming instead the clinician is asking about allopathic care treatments, such as prescription or over-the-counter medications.

You see a lot of Native Americans here, and all of us have our own different ways. It would be interesting just to hear one of the doctors ask if you used any kind of traditional medicine for, you know, maybe pain relief. They don't ask you. I guess that they do, but you just tell them Tylenol.

Multiple competing demands for time within the brief clinical encounter limited when and how clinicians discussed TM/CAM with patients. For example, several clinicians indicated that if they ask patients about the use of these practices, they do so typically only as part of an initial medical history.

\section{Safety and Efficacy Concerns}

Views about the safety and efficacy of the TM/CAM practices also appeared to influence communication. Clinicians, trained to base their therapeutic decision making on the best available scientific evidence, expressed skepticism where evidence of the effectiveness and safety of TM/CAM is lacking.

I use very little [TM/CAM], and I use it very cautiously, because being trained in Western medicine like I am.... It's always a lot more comfortable when, you know, several million people have used it and there's a bunch of studies out already and you can kind of see how it's going.

Some clinicians, driven by their concerns about the safety and efficacy of TM/CAM, reported an assertive approach aimed at dissuading patients from using TM/CAM by calling on their medical authority and expertise.

[Interviewer] If the use of [TM/CAM] does come up in the context of a patient whose diabetes isn't well controlled, we're wondering what you're trying to know about that use. 
[Clinician] I want to know what it is they're taking and the rationale for taking it. It's not always taking medicine, sometimes it's not taking medicine, because I've had people come and say, "Well I'm not taking my Lipitor because my neighbor told me it does this and it does that." Usually I can answer that with, "Well, where did they go to medical school?" and I think they get the idea right away that they shouldn't be listening to the neighbor and they should be listening to the doctor.

\section{DISCUSSION}

We found 3 main themes that largely determine whether and how communication about TM/CAM takes place between patients and their primary care clinicians: acceptance/nonjudgment, initiation of communication, and safety/efficacy concerns. Patients' perspectives about TM/CAM communication were clear and consistent. Most patients who are using TM/CAM for health or illness expect the clinician to initiate the discussion on this topic if communication is to occur. Patient data suggested clinician initiation, when carried out in a nonjudgmental fashion, would demonstrate openness to TM/CAM and would help patients overcome anticipated or previous negative interactions in discussions about TM/CAM. Patients usually did not expect their clinicians to be experts on the TM/CAM they were using.

Paradoxically, some clinicians interpreted the low levels of communication about TM/CAM as a sign of low use in their clinical practices. This assumption, together with the clinician's lack of understanding about TM/CAM, appeared to limit discussion of TM/ CAM in the brief clinical encounter. Many clinicians expressed skepticism about TM/CAM safety and effectiveness out of genuine concern for their patients, and some believed their duty is to protect patients from the potential adverse effects of certain practices or possible delay of effective conventional care resulting from TM/CAM use. Other clinicians, while still skeptical, see nonjudgmental discussions with their patients about TM/CAM to be a way to improve their understanding of and relationships with their patients. Many clinicians, however, mention limited time as a restricting factor.

This project aimed to better understand the dynamics of communication about TM/CAM between primary care clinicians and their patients, and to identify strategies for enhancing that communication. We focused on ethnic minority populations in which TM/CAM is an important part of everyday health practices. There has been little investigation of patientclinician communication about TM/CAM in ethnic minority populations. ${ }^{10,19,27-30}$ Although TM/CAM use is common in ethnic minority primary care populations, ${ }^{31-41}$ research conducted on disclosure and discus- sion of TM/CAM with primary care clinicians shows it is limited at best. ${ }^{6,37,38}$ Nondisclosure is found to be more common among minority groups, including Hispanics and Native Americans, as well as among indigent patients. ${ }^{37,39,41}$ One study has reported that patient anticipation of negative response to their TM/CAM use by clinicians is high, ${ }^{6}$ whereas 2 other studies suggest that clinicians are open to discussing this topic, perhaps more than patients realize. ${ }^{42,43}$ In contrast, we found variability among the clinicians interviewed in their openness to this discussion.

\section{Application}

Traditionally strategies to increase communication with patients about TM/CAM have recommended that clinicians acquire wider knowledge about specific TM/CAM therapies. We suggest investigating a different approach. We believe that clinicians must initiate this discussion, yet in so doing they do not have to be experts in TM/CAM therapies; they simply need to show nonjudgmental interest and candor regarding limited knowledge. Such an approach was preliminarily confirmed during our video vignette process, but this model will require rigorous investigation with actual patients and clinicians. ${ }^{44}$ Open and nonjudgmental questioning is consistent with patient-centeredness theory, ${ }^{8}$ which is intended to facilitate eliciting the patient's perspective, understanding the patient, acting in a manner consistent with patients' values, and involving patients in medical decision making. As well, patient disclosure of TM/CAM is correlated with having a physician with a participatory decision-making style. ${ }^{27}$

\section{Limitations}

Our research took place in Hispanic and Native American communities where TM/CAM use is an important component of personal health care, which could limit the generalizability of our findings. We believe, however, that the themes we identified as influencing TM/ CAM communication share a common basis with concepts about patient-centered communication in general. Data were collected from staff and patients of primary care clinics, so it is possible they may not represent the perspectives of people not entering primary care. The focus of our study, however, was on improving communication with patients seen in primary care clinics.

\section{Future Questions}

Our findings have implications for TM/CAM communication skills training that could be integrated into clinical curricula and continuing medical education. It may be easier to educate clinicians with brief training in targeted communication skills, which have been shown to increase clinician discussion of challenging 
topics. ${ }^{45,46}$ Future investigation should also explore factors contributing to why patients and clinicians are and are not comfortable with discussing TM/CAM. Such information would help gain further understanding as to what motivates patients to discuss TM/CAM and what motivates clinicians' willingness to listen.

To read or post commentaries in response to this article, see it online at http://www.annfammed.org/cgi/content/full/7/2/139.

Key words: Patient-physician relations; communication; complementary therapies; practice-based research; primary health care; traditional medicine

Submitted April 4, 2008; submitted, revised, August 8, 2008; accepted August 26, 2008

Versions of this research were presented at the New Mexico Tribal Health Research Summit, June 2006, Albuquerque, New Mexico; the Annual Meeting of the North American Primary Care Research Group, October 2006, Tucson, Arizona; the Navajo Nation Human Research Review Board Conference, September 2007, Window Rock, Arizona; and the Annual Meeting of the North American Primary Care Research Group, October 2007, Vancouver, British Columbia.

Funding support: This publication was made possible by grant No. 1 R21 AT 2323-01 from the National Center for Complementary and Alternative Medicine (NCCAM). Its contents are solely the responsibility of the authors and do not necessarily represent the official views of the NCCAM, or the National Institutes of Health.

Acknowledgments: We sincerely appreciate the efforts of community members, patients and clinicians who participated in this study.

\section{References}

1. Barnes PM. Complementary and alternative medicine use among adults: United States 2002. Adv Data. 2004;(343):1-19.

2. World Health Organization. Traditional Medicine Strategy 2002-2005. Geneva: World Health Organization; 2002.

3. Eisenberg DM, Davis RB, Ettner SL, et al. Trends in alternative medicine use in the United States, 1990-1997: results of a follow-up national survey. JAMA. 1998;280(18):1569-1575.

4. Eisenberg DM, Kessler RC, Van Rompay MI, et al. Perceptions about complementary therapies relative to conventional therapies among adults who use both: results from a national survey. Ann Intern Med. 2001;135(5):344-351.

5. Sleath B, Rubin RH, Campbell W, Gwyther L, Clark T. Ethnicity and physician-older patient communication about alternative therapies. J Altern Complement Med. 2001;7(4):329-335.

6. Adler SR. Disclosing complementary and alternative medicine use in the medical encounter: a qualitive study in women with breast cancer. J Fam Pract. 1999;13(2):214-222.

7. Herman CJ, Allen P, Hunt WC, Prasad A, Brady TJ. Use of complementary therapies among primary care clinic patients with arthritis. Prev Chronic Dis. 2004;1(4):A12.

8. Epstein RM, Franks P, Fiscella K, et al. Measuring patient-centered communication in patient-physician consultations: theoretical and practical issues. Soc Sci Med. 2005;61(7):1516-1528.

9. Corbin Winslow L, Shapiro H. Physicians want education about complementary and alternative medicine to enhance communication with their patients. Arch Intern Med. 2002;162(10):1176-1181.
10. Flannery M. Communication about complementary and alternative medicine: perspectives of primary care clinicians. Altern Ther Health Med. 2006;12(1):56-63.

11. Tasaki K, Maskarinec G, Shumay DM, Tatsumura Y, Kakai H. Communication between physicians and cancer patients about complementary and alternative medicine: exploring patients' perspectives. Psychooncology. 2002;11(3):212-220.

12. Borkan J, Neher JO, Anson O, Smoker B. Referrals for alternative therapies. J Fam Pract. 1994;39(6):545-550.

13. Cherrington A, Lewis CE, McCreath $\mathrm{HE}$, Herman CJ, Richter DL, Byrd T. Association of complementary and alternative medicine use, demographic factors, and perimenopausal symptoms in a multiethnic sample of women: the ENDOW study. Fam Community Health. 2003;26(1):74-83.

14. Zeilmann CA, Dole EJ, Skipper BJ, McCabe M, Dog TL, Rhyne RL. Use of herbal medicine by elderly Hispanic and non-Hispanic white patients. Pharmacotherapy. 2003;23(4):526-532.

15. Van Sickle D, Morgan F, Wright AL. Qualitative study of the use of traditional healing by asthmatic Navajo families. Am Indian Alsk Native Ment Health Res. 2003;11(1):1-18.

16. Higginbotham JC, Trevino FM, Ray LA. Utilization of curanderos by Mexican Americans: prevalence and predictors. Findings from HHANES 1982-84. Am J Public Health. 1990;80(Suppl):32-35.

17. Kim C, Kwok YS. Navajo use of native healers. Arch Intern Med. 1998;158(20):2245-2249.

18. Dole EJ, Rhyne RL, Zeilmann CA, Skipper BJ, McCabe ML, Dog $\mathrm{TL}$. The influence of ethnicity on use of herbal remedies in elderly Hispanics and non-Hispanic whites. J Am Pharm Assoc. 2000;40(3):359-365.

19. Shelley BM. Integrative medicine research in New Mexico: lessons from the published literature. Complement Health Pract Rev. 2006;11(2):107-119.

20. Binns HJ, Lanier D, Pace WD, Galliher JM, Ganiats TG, Williams R. Describing primary care encounters: the Primary Care Network Survey and the National Ambulatory Medical Care Survey. Ann Fam Med. 2007;5(1):39-47.

21. Sussman AL, Williams RL, Leverence R, Gloyd PW Jr, Crabtree BF. The art and complexity of primary care clinicians' preventive counseling decisions: obesity as a case study. Ann Fam Med. 2006;4(4):327-333.

22. Ralston S, Kellett N, Williams RL, Schmitt C, North CQ. Practicebased assessment of tobacco usage in Southwestern primary care patients: a research involving outpatient settings network (RIOS Net) study. J Am Board Fam Med. 2007;20(2):174-180.

23. Williams RL, Snider R, Ryan MJ. A key informant "tree" as a tool for community oriented primary care. The Cleveland COPC Group. Fam Pract Res J. 1994;14(3):273-280.

24. Miller WL, Crabtree B. The dance of interpretation. In: Miller WL, ed. Doing Qualitative Research. Thousand Oaks CA: Sage; 1999.

25. NVivo [computer program]. Version 2. Doncaster, Victoria, Australia: QSR International; 2002.

26. Crabtree B, Miller WL. Using codes and code manuals: a template organizing style of interpretation. In: Miller WL, ed. Doing Qualitative Research. Thousand Oaks CA: Sage; 1999.

27. Sleath B, Callahan L, DeVellis RF, Sloane PD. Patients' perceptions of primary care physicians' participatory decision-making style and communication about complementary and alternative medicine for arthritis. J Altern Complement Med. 2005;11(3):449-453.

28. Frankel RM, Sung SH, Hsu JT. Patients, doctors, and videotape: a prescription for creating optimal healing environments? J Altern Complement Med. 2005;11(Suppl 1):s31-s39.

29. Cooper-Patrick L, Gallo JJ, Gonzales JJ, et al. Race, gender, and partnership in the patient-physician relationship. JAMA. 1999; 282(6):583-589. 
30. Johnson RL, Roter D, Powe NR, Cooper LA. Patient race/ethnicity and quality of patient-physician communication during medical visits. Am J Public Health. 2004;94(12):2084-2090.

31. Howell L, Kochhar K, Saywell R Jr, et al. Use of herbal remedies by Hispanic patients: do they inform their physician? J Am Board Fam Med. 2006;19(6):566-578.

32. Keith VM, Kronenfeld JJ, Rivers PA, Liang SY. Assessing the effects of race and ethnicity on use of complementary and alternative therapies in the USA. Ethn Health. 2005;10(1):19-32.

33. Kronenberg F, Cushman LF, Wade CM, Kalmuss D, Chao MT. Race/ ethnicity and women's use of complementary and alternative medicine in the United States: results of a national survey. Am J Public Health. 2006;96(7):1236-1242.

34. Mackenzie ER, Taylor L, Bloom BS, Hufford DJ, Johnson JC. Ethnic minority use of complementary and alternative medicine (CAM): a national probability survey of CAM utilizers. Altern Ther Health Med. 2003;9(4):50-56.

35. Lopez RA. Use of alternative folk medicine by Mexican American women. J Immigr Health. 2005;7(1):23-31

36. Bair YA, Gold EB, Greendale GA, et al. Ethnic differences in use of complementary and alternative medicine at midlife: longitudinal results from SWAN participants. Am J Public Health. 2002;92(11):1832-1840.

37. Graham RE, Ahn AC, Davis RB, O'Connor BB, Eisenberg DM, Phillips RS. Use of complementary and alternative medical therapies among racial and ethnic minority adults: results from the 2002 National Health Interview Survey. J Natl Med Assoc. 2005;97(4):535-545.
38. Buchwald D, Beals J, Manson SM. Use of traditional health practices among Native Americans in a primary care setting. Med Care. 2000;38(12):1191-1199.

39. Planta M, Gundersen B, Petitt JC. Prevalence of the use of herbal products in a low-income population. Fam Med. 2000;32(4):252-257.

40. Shapiro K, Gong WC. Use of herbal products for diabetes by Latinos. J Am Pharm Assoc. 2002;42(2):278-279.

41. Marbella AM, Harris MC, Diehr S, Ignace G. Use of Native American healers among Native American patients in an urban Native American health center. Arch Fam Med. 1998;7(2):182-185.

42. Crock RD, Jarjoura D, Polen A, Rutecki GW. Confronting the communication gap between conventional and alternative medicine: a survey of physicians' attitudes. Altern Ther Health Med. 1999;5(2):61-66.

43. Frenkel MA, Borkan JM. An approach for integrating complementary-alternative medicine into primary care. Fam Pract. 2003;20(3):324-332.

44. Barrett B, Rakel D, Chewning B, et al. Rationale and methods for a trial assessing placebo, echinacea, and doctor-patient interaction in the common cold. Explore (NY). 2007;3(6):561-572.

45. Stewart M, Brown JB, Hammerton J, et al. Improving communication between doctors and breast cancer patients. Ann Fam Med. 2007;5(5):387-394.

46. Ryan GL, Skinner CS, Farrell D, Champion VL. Examining the boundaries of tailoring: the utility of tailoring versus targeting mammography interventions for two distinct populations. Health Educ Res. 2001;16(5):555-566. 